THE EARTHQUAKE IN SANTA MONICA BAY, CALIFORNIA, ON AUGUST 30, 1930

\author{
By B Gutenberg, C F. Richter, and H O. Woon
}

An earthquake which barely attained destructive violence over a small area occurred at about 4: 40 p.m., Pacific Standard Time, on August 30, 1930 (at $0^{h} 40^{m}$, G.C.T., on August 31, 1930). It originated near the coast a short distance west of Santa Monica, a suburb of Los Angeles. California. The shock was perceptible at distances up to about 160 kilometers (100 miles) from the adopted epicenter given below.

Just to the north of this epicenter the Santa Monica Mountarns rise steeply from the adjacent plain and ocean to heights which range from less than 300 to more than 850 meters (approximately 1,000 to 2,800 feet) above sea. From this point the range extends to the eastward for some 30 kilometers ( 20 miles) and to the westward for nearly 50 kilometers ( 30 miles), a total length of about 80 kilometers ( 50 miles) in an east-west direction. It attains a maximum width, north and south, of somewhat less than 16 kilometers (10 miles). Thus this narrow mountain belt cuts directly throngh the area of hardest shaking. And, of course, comparatively few people live or work on its higher slopes. To the south of this mountainous land--toward the cast is the densely populated area of the city of Los Angeles and its western suburbs; toward the west are the waters of Santa Monica Bay and the ocean beyond. To the north of the mountain belt-toward the east is the plain of the San. Fernando Valley, thickly settled in some parts, sparsely in others; and toward the west are the Simi Hills and Simi Valley, inhabited by relatively few. Beyond these limits, also, the region affected by the shock presents a complicated pattern of mountain, plain, and sea, with corresponding variations in the density of population and in surface conditions, materials, and structures.

There is thus a complex geologic terrane which has been studied intensively, especially in the central region, from which was obtained an unusually large number of observations on the action of the shock. Excellent seismometric records were written, also, under unusually favorable circumstances in some respects. Consequently, this shock merits careful study and description. 


\section{INTENSITY AND ISOSEISMALS}

More than three hundred reports on the behavior and effects of this earthquake, submitted by co-operative observers resident within and just outside the area over which the shock was perceptible, were made available for this study by the United States Coast and Geodetic Survey through the Field Inspector at San Francisco. It is a pleasure to acknow1edge the great assistance thus rendered by the Survey. Further information was available from press reports, additional personal observations, and brief field investigations by two of the authors (Richter, Wood). Therefore, although the information in regard to intensity is much less voluminous and less complete than has been available on some occasions in other parts of the world, the items of information regarding this shock are more numerous and more suitably and adequately distributed over the area of perceptibility than ever before for a shock in Southern California. Notwithstanding this, however, there still is by no means enough information to afford a minutely detailed picture of the distribution of apparent intensity. Also, but little of the data is precise enough or explicit enough to permit critical study. On the whole very praiseworthy, necessarily in most instances the reports were not made by trained or expert investigators, and in many instances it is difficult to judge which of two grades of intensity is indicated by the data submitted. However, the reports on this occasion serve general purposes very well and give grounds for hope that st1l better results will be obtained in future cases.

A few more than forty of the reports at hand state that the shock was "not felt." Many of these are from places outside the area of perceptibility Some mean merely that the shock was "not noticed" by the observer and those he consulted. A few probably indicate anomalous behavior, and a few must be inaccurate. There is, however, a sufficient number of useful reports to outline in general the boundary between the area within which the shock was perceptible and the surrounding country in which it was not.

The remaining information, including more than two hundred and fifty reports from private individuals, postmasters and other public officials, and representatives of corporations. co-operating with the Survey, has enabled us to make a reasonably adequate study of the shock-intensity and its range and distribution over the area affected.

The results of this study are exhibited on the maps (Figs. 1 and 2). Generalized 1sosersmals are shown on the small-scale map (Fig. 1), distıngurshing the areas affected predominantly by intensity of grades $V$. 


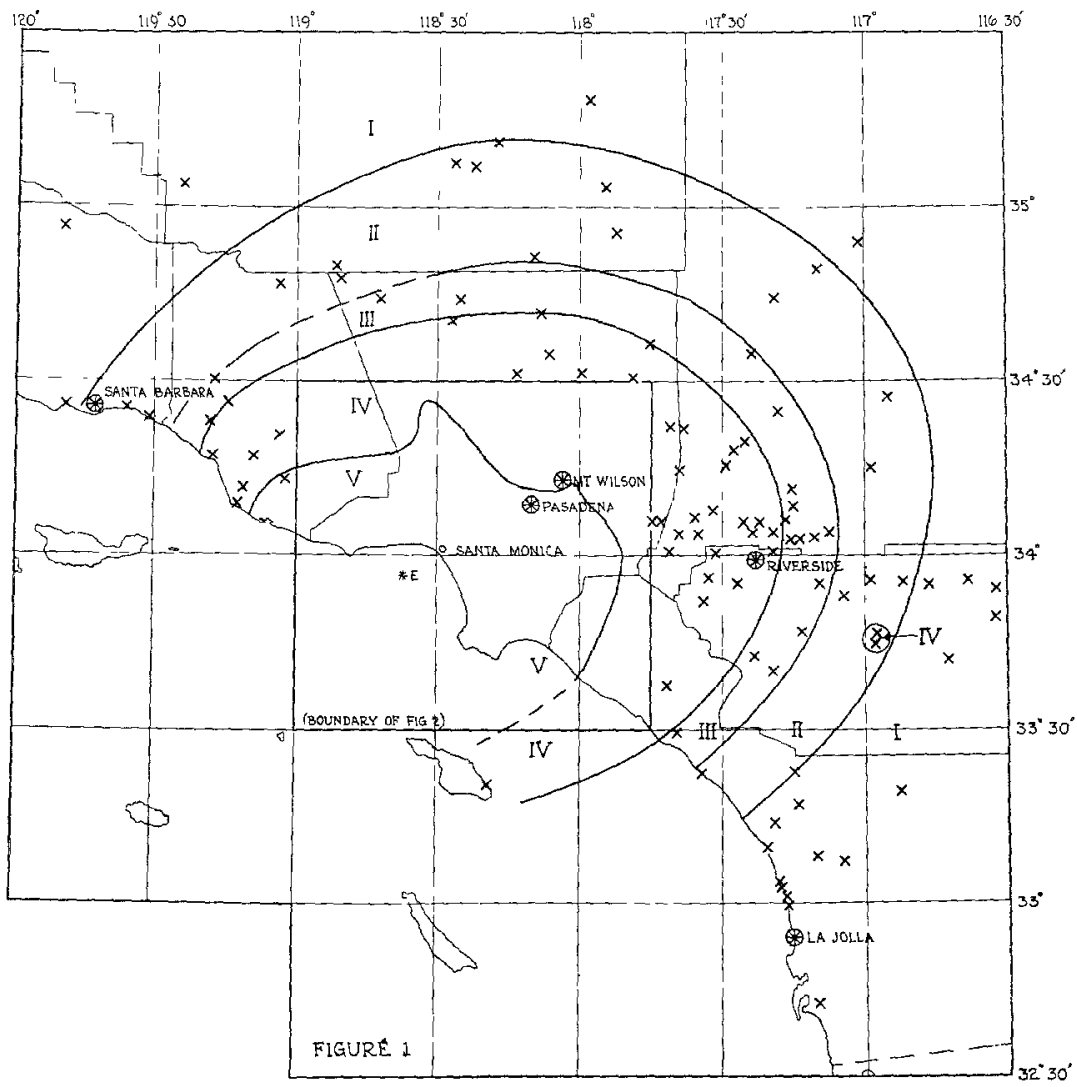

FIG. 1 -Approximate outer 1soseismal curves, earthquake of August 30, 1930

IV, III, and II and the surrounding country affected by grade I. according to the Modified Mercalli Intensity Scale of 1931. ${ }^{1}$ On this map $X$-marks show the places from which reports were received, outside a central area which is covered by the large-scale map (F1g. 2), the boundary of which is indicated on Figure 1 Reports "not felt" were received also from two places heyond the limits of the map-Gaviota, on the coast west of Santa Barbara, and Twenty-Nine Palms, on the desert east and a little north of Riverside. Figure 1 shows also the locations of the seismologic stations at Santa Barbara, Pasadena, Mount W1son, River-

${ }^{x}$ Harry O. Wood and Frank Neumann, "Modified Mercalli Intensity Scale of 1931," Bulletin of the Seismological Soctety of Amenca, 21, 277. 


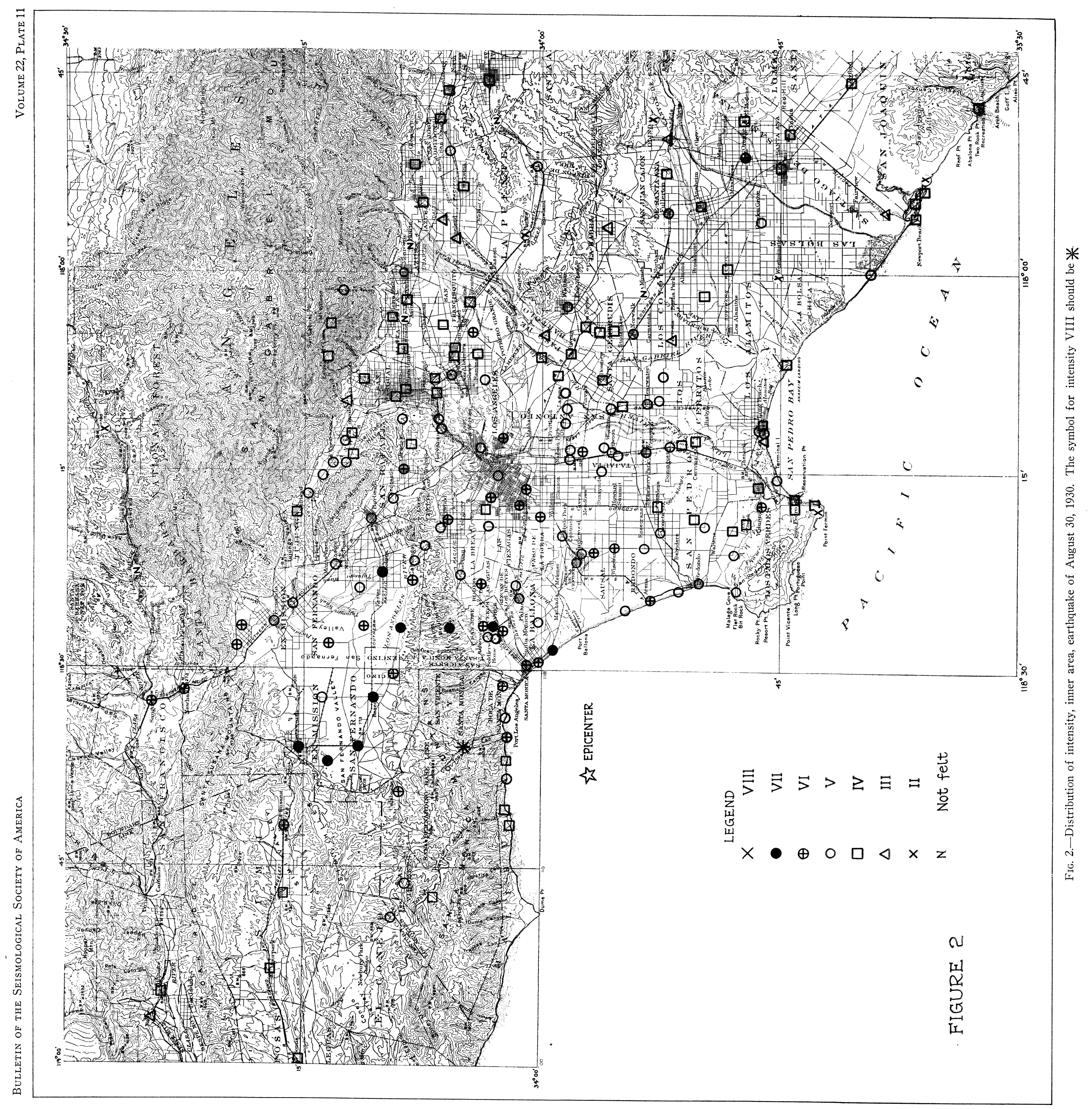


s1de, and La Jolla. The stations at Haiwee and Tinemaha are a little west of north from Riverside, beyond the limits of the map.

The east-west elongation shown by the outer isoseismal curves is possibly real, though the distribution of places from which information is available may tend to overemphasize it. Nothing definite is known as to elongation of the source, either as a transient phenomenon of this shock only or as a more permanent geologic condition. On the other hand, interspersed among hilly to mountainous areas are several prominent valleys or basins which hold deep deposits of loose materials, alluvium and unconsolidated rocks, thus forming districts especially sensitive to shaking. These are located along an east-west trend, and they are much more occupied than the slopes above them, some being very densely populated in parts. Places of report thus tend to show a similar distribution and, consequently, there is some probability that this may be in part a reason for the elongation of the isoseismals in this direction--a statistical rather than a physical reason. This probability finds some support from a northern elongation, or bulge, of the area of higher intensity north of the epicenter, and in this latter case some physical reason seems indicated.

The large-scale map (Fig. 2), bounded by the meridians $117^{\circ} 45^{\prime}$ and $119^{\circ} 00^{\prime}$ west longitude, and the parallels $33^{\circ} 30^{\prime}$ and $34^{\circ} 30^{\prime}$ north latitude, includes the area of stronger shaking. This map shows the topographic contours and the drainage, and the status of occupation and culture some thirty to forty years ago. In many places the latter has undergone great change since the survey. On this map locations from which data on intensity are available are shown with much accuracy by symbols which also denote the value of the intensity at these places, as indicated by the reports, in terms of the Modified Mercalli Intensity Scale of 1931. It is clear that the reports must have been influenced by surface-ground conditions, and by the nature of the indicators available or observed in the particular cases, as well as by the experience and psychology of the observers. Therefore, even though ground conditions have been taken into account in obvious cases in forming judgments as to the intensity indicated by the reports, apparent inconsistencies are to be expected, and these appear in abundance. As the map is legible with respect to relief and drainage, and the apparent intensity is shown at every place of report within the central area, it seems best to present this evidence on its merits, without drafting isoseismals, or any further adjustment of report values. The more important peculiarities thus brought out are discussed below.

Intensity low in grade VIII, Modified Mercalli Intensity Scale of 
1931, is indicated by one report only, from the Topanga Post Office, situated at an elevation of about 225 meters (750 feet) in the Santa Monica Mountains about 15 kilometers ( 9 miles) north and a little east from the epicenter.

Intensity of grade VII, in most instances low in this grade, is ind1cated by reports from only nine scattered places.

One of these is in the Santa Monica Mountains area on metamorphic stratified rock, probably of Triassic age, about 24 kilometers (15 miles) east-northeast from the epicenter. The intensity at this point seems well determined, unmodified by loose or wet material underground. This, possibly, is a critical value.

Four of the places are in the west and southwest parts of the San Fernando Valley, where loose or only slightly consolidated material is deep; and two are along the south margin of this valley near its east end, where deep unconsolidated material is probably saturated with water from small depth downward. While the intensity at these points appears well indicated, it may be higher than normal at such distances from the epicenter because of the foundation ground.

The two remaining places are in the western part of the Los Angeles plain south and east of Santa Monica and only about 15 to 20 kilometers ( 9 to 12 miles) from the epicenter. Nevertheless. neighboring places were affected by apparent intensity of grade VI, and even grade V. Owing to the influence of complex factors the reports from these two localities are considered less significant than the others.

To enclose all the places where intensity VII is indicated with reasonable certainty, an approximately circular arc about the epicenter, with radius of 35 kilometers ( 22 miles), or slightly more, would be required. Such a curve, however, would enclose also a great many points where the apparent intensity is indicated as less. So high intensity is not characteristic of the area thus encircled Though there were within it localities where the intensity seems surely VII, a large part of such an area appears to have been affected by intensity VI or less. The information at hand is not sufficient to delimit a normal, or even a minimum, area characterized by intensity of grade VII.

This illustrates well the fact that over much of the area of stronger shaking the intensity indicated by the reports shows a "spotted" distribution. There are numerous places (single points, or segregated groups), well separated from each other, where intensity of a given value appears well developed, which are surrounded by places where intensity one or two grades lower is indicated by the reports, apart from special under- 
ground or structural conditions. A strong suggestion arises, supported by many facts, that the acceleration manifested at many places was higher than the observed effects, as a whole, would indicate. For a fairly strong earthquake the shock was of relatively brief duration, and the more violent shaking may have subsided before there was time to produce generally the effects usually characteristic of the force experienced. This may afford a true explanation of the "spotted" intensity picture. This may also be due to the interference of seismic waves, which is discussed below.

Again, to enclose all the places where intensity of grade VI is indicated by the reports, an approximately circular arc, with radius of 45 kilometers (28 miles), or perhaps somewhat more, would be required, but once more this intensity is not characteristic of so large an area as is thus denoted. Except for four places, to the north and a little to the east from the epicenter -in which azimuth inner intensity curves would bulge outward-an arc with radius of 40 kilometers (25 miles), or less, would enclose the places where intensity VI was manifested, but still once again much of the area thus bounded was affected by intensity $V$ or less, according to the reports. Especially to the northwest, on hilly ground, there is no indication that intensity VI extended so far from the epicenter.

Also, effects of grade $\mathrm{V}$ in some instances are indicated at distances slightly in excess of 60 kilometers ( 37 miles), but again an arc with this radius would enclose much territory affected by lesser intensity.

Normal, or minimum, radii for areas marked by intensity VI, and V, could perhaps be approximated, but with considerable uncertainty.

A few places require special comment.

Investigations in the field along the coast west of Santa Monica-a narrow area of beach, terrace, and hill slope--definitely established lower values of intensity at distances of 10 to 15 kilometers ( 6 to 9 miles) from the epicenter than those manifested on the higher rocky slopes to the north, in the San Fernando Valley at distances of 25 to 35 kilometers (15 to 22 miles), and on the adjacent Los Angeles plain about Santa Monica. No explanation for this anomaly occurs to us, unless possibly it may be due to the angle of emergence of the shock rays, or to interference of seismic waves, both of which seem very unlikely.

An area, including a considerable tract formerly marshy, situated east of Santa Monica, west of Los Angeles, and a short distance south of the Santa Monica Mountains, was apparently affected by lesser intensity than the immediately surrounding country. This anomaly is striking, since 
higher rather than lower intensity would naturally be expected in this case.

The neighborhood of Harbor City, just north of the San Pedro Hills. exhibited higher intensity, VI, than the surrounding ground, without clearly apparent reason.

A similar statement holds for the vicinity of Wilmar, intensity VI, east-northeast of Los Angeles and south-southeast of Pasadena.

In the eastern and southeastern part of the Los Angeles plain are several places, separated from each other, along a north-south line where intensity $\mathrm{V}$ is indicated by the reports, while all around intensity IV prevailed, but with near-by places affected by intensity III or II. The underground conditions in these places, though favorable to strong shaking, are not known to be more so than in the adjacent area.

A similar statement holds for two or three places in the Cucamonga Valley east of the San José Hills and south of the San Gabriel Mountanns, at distances of 90 to 100 kilometers ( 55 to 60 miles) from the epicenter.

At Monrovia, at the south base of the San Gabriel Mountains east of Pasadena, intensity $\mathrm{V}$ is indicated by the reports, and also at Roberts' Camp and at the near-by ranger station at an elevation of about 750 meters (2.500 feet) on the crystalline rock north of Sierra Madre. The value of the intensity here is well supported and consequently significant, though not easy to understand. The locality is distant about 63 kilometers ( 39 miles) from the epicenter. This observation is important for any critical consideration of the true energy of the shock.

Contrasting with it, at Duarte, less than 5 kilometers ( 3 miles) southeast of Monrovia, the shock was not felt, or not noticed. Previous experience indicates that this report is reliable. As the ground at Duarte is deep unconsolidated wash gravel and alluvium. probably water-saturated at no great depth, this insensitiveness to shock is strikingly anomalous.

Anomalously high intensity. $\mathrm{V}$, was reported from Riverside, distant about 117 kilometers ( 73 miles) east of the epicenter; and at San Jacinto, IV, and Hemet, IV, at an epicentral distance of about 160 kilometers (100 miles).

Further, there were several reports of high surf along the coast following the shock. However, apart from interference with the wave progression just at the time of the shock, there were no sersmic wave effects, and the high surf reported later was probably of storm origin entirely unconnected with the shock.

None of the apparent anomahes appear related to geological conditions, except as mentioned above, nor to the known faults which traverse 
the region, with the possible exception of the high intensity at San Jacinto and Hemet, which are very near to the active San Jacinto Fault. These two places, however, are also situated on deep unconsolidated material, possibly water-soaked at depth.

Tentative isoseismals for the region shown on Figure 2 suggest a peculiar alignment of points of abnormally high and low intensity which vaguely resembles the nodes and loops of an interference pattern. This irregularity, however, may be due, wholly or 11 part, to the brief duration of hard shaking, as mentioned above. The reports, moreover, are neither sufficiently accurate nor numerous enough to warrant any conclusion. There is, of course, difficulty with physical mechanisms to account for such an interference effect. One possibility would be interference between the direct transversal waves and the surface shear waves. Another possibility would be the occurrence of a double shock, with resulting interference. No emphasis, of course, is placed upon these suggestions at the present time. However, the hypothesis of a double shock is of some interest for other reasons, as is discussed below.

A few reports mentioned more than one shock. In three cases two shocks were described so definitely that there can be little doubt of their occurrence. Also in four other cases two shocks were described with less definiteness. It is not considered probable that these reports were due to observations of separate phases as distinct shocks. On the other hand, it frequently happens that two or more shocks are reported in cases where only one shock can be verified; further, there is no mention of two shocks, or of a double shock, at Topanga, where the highest intensity was reported, nor at points in the San Fernando Valley, where fairly high intensity prevailed. Moreover, there is no indication of two shocks on the instrumental records. However, if a shock of relatively shallow origin and comparatively smaller energy had originated under the western end of the San Fernando Valley, say twenty seconds after the first shock, instrumental record of this might well have been masked completely at the nearer stations by the larger waves of the first shock, while at the more distant stations such a shock would not have written amplitudes large enough to be discriminated clearly among the later waves of the first shock; yet it might have been sufficient to augment the intensity near its origin, and so explain the higher values in the western San Fernando Valley and immediately to the north. Though not strongly suggested, such a possibility should not be ignored. Against it is the fact that there was no report of two shocks from this particular district.

Mention may be made of two further shocks, the first on April 24, 
1931, originating off the coast southwest of Redondo, and the second on April 29, 1931, which originated apparently beneath the western part of the San Fernando Valley. Epicenters and origin-times for these have been determined ${ }^{2}$ as follows:

$\phi=33^{\circ} 46^{\prime}$ N.. $\lambda=118^{\circ} 29^{\prime}$ W., at ( $10^{\mathrm{h}} 57^{\mathrm{m}} 55^{\mathrm{s}}$, P.S.T.) $18^{\mathrm{h}} 27^{\mathrm{m}} 55^{\mathrm{s}}$,

G.C.T., on April 24, and

$\phi=34^{\circ} 15^{\prime}$ N., $\lambda=118^{\circ} 39^{\prime}$ W., at $\left(4^{\mathrm{h}} 41^{\mathrm{m}} 37^{\mathrm{s}}\right.$, P.S.T $) 12^{\mathrm{h}} 41^{\mathrm{m}} 37^{\mathrm{s}}$, G.C.T., on April 29

\section{Instrumental DATA}

The shock was registered at the various stations ${ }^{3}$ as follows:

\section{TABLE I}

Arrival Times, August 30, 1930, P.M, P S.T.

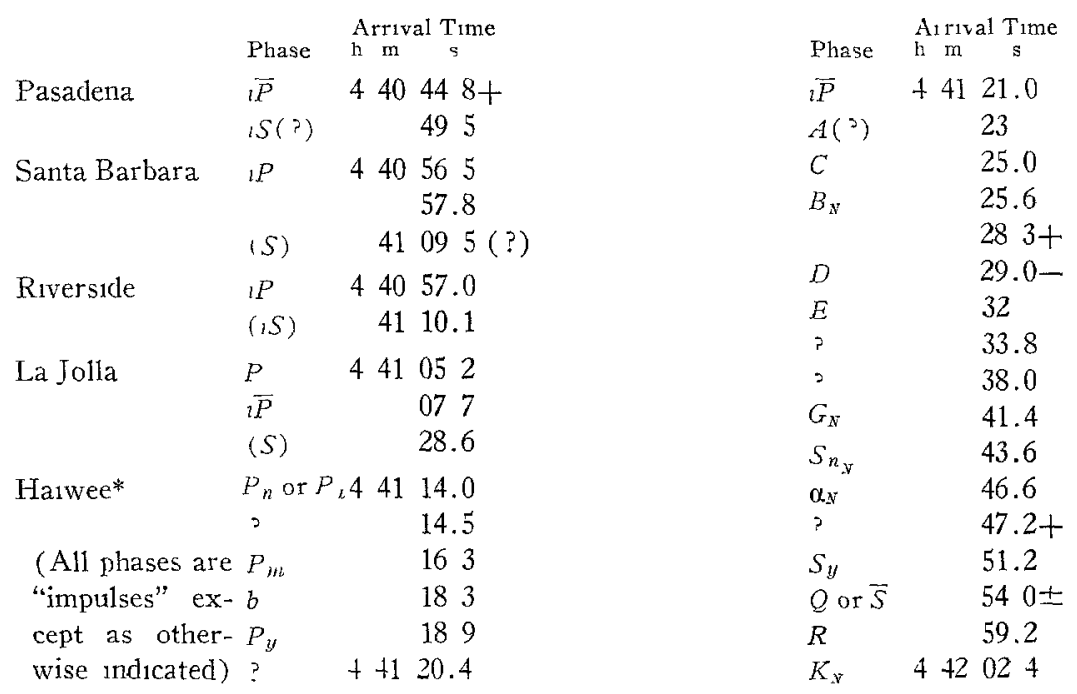

* For phase 5 y rabols employed, see B. Gutenberg, op cit,

2 B. Gutenberg, "Travel Time Curves at Small Distances, and Wave Velocities in Southern California," Bettrage zur Geophysik, 35, 6-45, 1932.

3 The constants of these stations were given in Bulletin of the Setsrnological Society of America, 21, 188-189, 1931, with the exception of the station at the Lick Observatory, for which the constants are as follows:

$\phi=37^{\circ} 20^{\prime} 24^{\prime \prime} 5 \mathrm{~N} ., \lambda=121^{\circ} 38^{\prime} 34^{\prime \prime} \mathrm{W} ., \mathrm{h}=1281.7 \mathrm{~m} .(4,202.25 \mathrm{ft}$. 


\section{TABLE I-Continued}

\begin{tabular}{|c|c|c|c|c|}
\hline & Phase & $\underset{\mathrm{ln}}{\text { Arrival Time }}$ & Phase & $\begin{array}{l}\text { Arrival Time } \\
\mathrm{n} m \mathrm{~s}\end{array}$ \\
\hline \multirow{6}{*}{$\begin{array}{l}\text { Lick Observatory } \\
\text { ( } N \text {-S compo- } \\
\text { nent only) }\end{array}$} & $e$ & 44140.4 & $1 g_{E}$ & 44318.1 \\
\hline & $\imath$ & 42.7 & $e g_{N}$ & 196 \\
\hline & $e$ & 46.2 & & 27 \\
\hline & $\imath$ & 48.4 & $e(P)$ & 39 \\
\hline & $S(?)$ & 4200.4 & iN & 49 \\
\hline & $e$ & 07.2 & ta & 57.4 \\
\hline \multirow[t]{5}{*}{ Berkeley } & $e(?)$ & 44155.2 & $2 S_{m}$ & 4405.0 \\
\hline & $\imath(?)$ & 57.7 & $i \boldsymbol{\beta}_{E}$ & $11+$ \\
\hline & & 4208 & $e \beta_{N}$ & 15.4 \\
\hline & $\imath(\bar{P} ?)$ & 16 & $\frac{13 y}{c}=0$ & 24 \\
\hline & $i$ & 23.5 & $\imath U_{X}$ & 30.0 \\
\hline \multirow[t]{4}{*}{ Tucson* } & $e b_{B}$ & $44233+$ & ${ }_{\imath} U_{B}$ & $30.8+$ \\
\hline & $e \bar{P}_{N}\left({ }^{2}\right)$ & 45 & $\imath J_{\bar{E}}$ & $38+$ \\
\hline & $\vec{P}_{E}(?)$ & 46.9 & $\imath R_{N}$ & 42.0 \\
\hline & $\imath B_{E}($ ? $)$ & $\begin{array}{lll}4 & 43 & 06.4\end{array}$ & $\imath R_{z}(P)$ & 44446.1 \\
\hline
\end{tabular}

Time corrections were not available at Mount Wilson, where, however, a conspicuous phase was registered 5.5 seconds, and a less conspicuous phase about 8 seconds, after the beginning on the $N-S$ record, while on the $E-W$ record a doubtful phase was indicated 6.5 seconds after the beginning.

No time corrections were available at Tinemaha, where, however, direct readings gave phase indications at intervals as follows, compared with the phases indicated by the transmission-time curvet for $\Delta=351$ kilometers, the calculated epicentral distance of Tinemaha:

TABLE II

\begin{tabular}{|c|c|c|c|c|c|c|c|}
\hline & $\begin{array}{c}\text { Observed } \\
\text { s }\end{array}$ & Phase & $\begin{array}{l}\text { Transmis- } \\
\text { sion Ttme } \\
\text { Curve } \\
\text { s }\end{array}$ & & $\begin{array}{c}\text { Observed } \\
\mathrm{s}\end{array}$ & Phase & $\begin{array}{l}\text { Transmis- } \\
\text { sion Time } \\
\text { Curve } \\
\text { s }\end{array}$ \\
\hline$e$ & 50.0 & $P_{n}$ & 50.0 & $t$ & 594 & $P_{y}$ & 597 \\
\hline$e$ & 51.3 & $P_{x}$ & 511 & & - & $c$ & 605 \\
\hline 1 & 51.9 & & & $\imath$ & 614 & & \\
\hline$e_{E}{ }^{2}$ & 525 & $a$ & 524 & 1 & 632 & $\bar{P}$ & 631 \\
\hline $\int(1)$ & $55.6\}$ & & 553 & $i$ & 656 & & \\
\hline$i_{N}$ & $56.1\}$ & $P_{m}$ & 553 & & & $A$ & 66.0 \\
\hline$(t)$ & 566 & & & $1_{E}^{2}$ & 676 & $C$ & 676 \\
\hline (i) & 57.7 & $b$ & 578 & $\imath_{N}$ & 68.2 & & \\
\hline 2 & 58.3 & & & $e$ & 704 & $d$ & 70.1 \\
\hline
\end{tabular}

\footnotetext{
4 B Gutenberg, op. cut.
} 


\begin{tabular}{|c|c|c|c|c|c|c|c|}
\hline & & & ABLE I & $\operatorname{Con}$ & & & \\
\hline & $\begin{array}{c}\text { Obse1ved } \\
\text { s }\end{array}$ & Phase & $\begin{array}{c}\text { Transmis- } \\
\text { sion Time } \\
\text { Curve } \\
\mathrm{s}\end{array}$ & & $\begin{array}{c}\text { Observed } \\
\text { s }\end{array}$ & Phase & $\begin{array}{c}\text { Transmis } \\
\text { sion Time } \\
\text { Curve } \\
\text { s }\end{array}$ \\
\hline (1) & 71.1 & $B$ & 709 & (a) & 976 & & \\
\hline$c$ & 723 & $D$ & 72.1 & & & $S_{m}$ & 100.2 \\
\hline & & $E$ & 76.2 & $(a)$ & 101.6 & & \\
\hline (b) & 78.3 & $e$ & 785 & (a) & 102.0 & $\beta$ & 102.4 \\
\hline & & $f$ & 83.8 & 1 & 104.8 & $S_{y}$ & 105.1 \\
\hline 1 & 88.7 & $F$ & 88.5 & $i_{E}$ & 1082 & $Q$ or $\bar{S}$ & 108.5 \\
\hline$i$ & 892 & $S_{n}$ & 89.5 & & & $\tilde{U}$ & 111.0 \\
\hline$e$ & 91.7 & $S_{x}$ & 91.5 & & & $J$ & 113.6 \\
\hline$\imath$ & 950 & $\mathrm{~N}$ & 946 & $l$ & 117.5 & $R$ & 117.7 \\
\hline$l_{E}$ & 964 & $\alpha$ & 96.9 & & & & \\
\hline
\end{tabular}

The direction of initial earth displacement at those stations where it could be estimated appears as follows :

At Pasadena, to the north, to the east, and upward

At Mount Wilson, to the north and to the east

At Riverside, to the south (followed immediately by much stronger motion to the north) and to the east

At Santa Barbara, to the north and to the west

At La Jolla, complicated by microseisms

At Haiwee, to the north and to the west (followed immediately by a sharp shift to the east)

At Tinemaha, to the north and to the east

All these indications point to compression.

Figure 3 shows the beginning of motion on several seismograms.

\section{Determination of Epicenter}

It is to be noted that motion began sharply at Santa Barbara at $4^{\mathrm{h}} 40^{\mathrm{m}} 56^{\circ} 5$, and at Riverside at $4^{\mathrm{h}} 40^{\mathrm{m}} 57^{\mathrm{s}} 0$. Therefore, it is clear that the origin was practically equidistant from these two stations However, the waves arriving at Santa Barbara may have been subject to a delay not exceeding half a second (probably less) on account of a thick body of sedimentary rock which lies beneath the station. Even if this contingency is allowed for, increasing the difference in time of arrival at Santa Barbara and Riverside to one second (or a little less), the difference in distance can hardly be as much as eight kilometers. However, by some very small distance. the origin is nearer to Santa Barbara than to Riverside. 

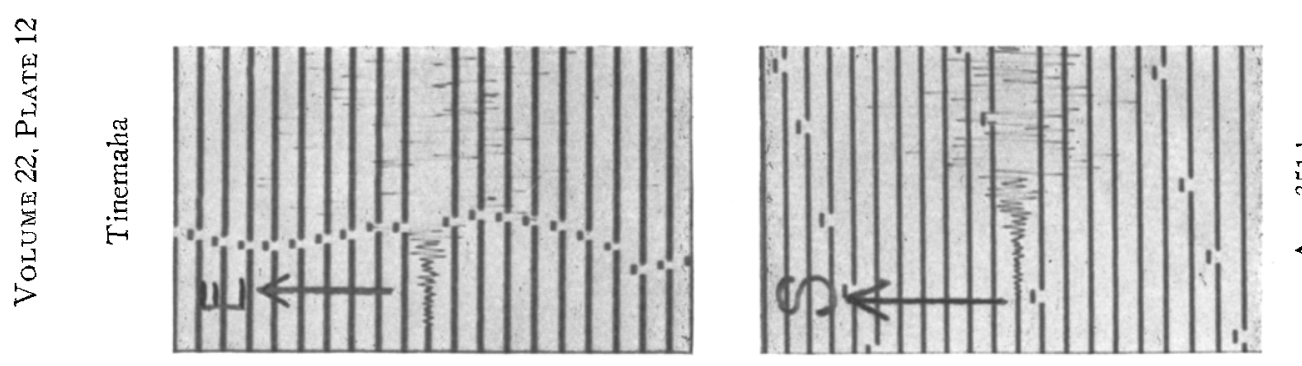

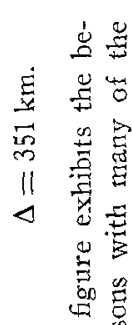
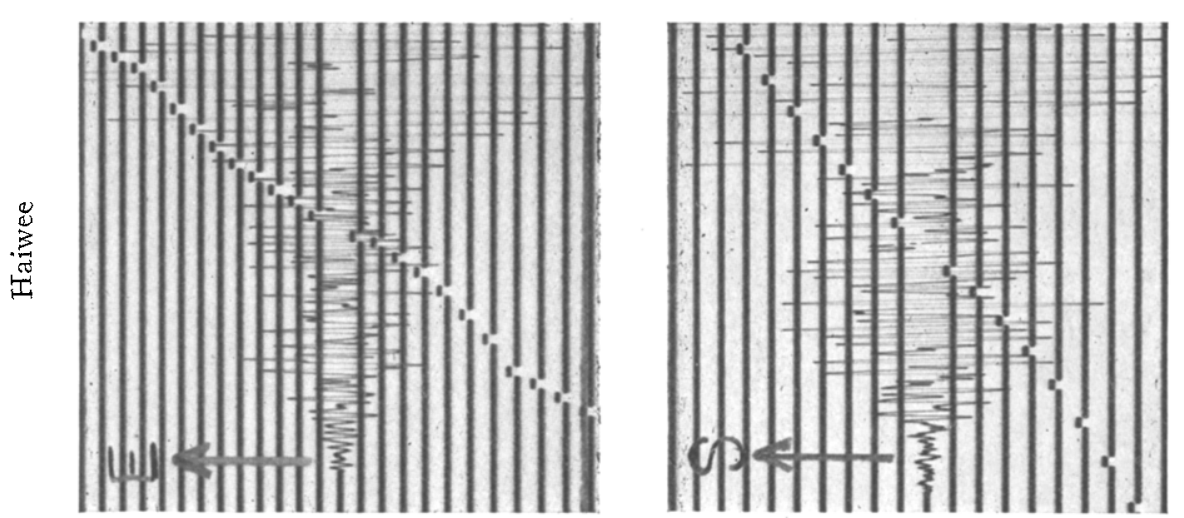

焉

o.

E 9

$+\quad \vec{z}$

i⿱宀

il $\mathrm{b}$

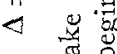

吾。

志㟔

i
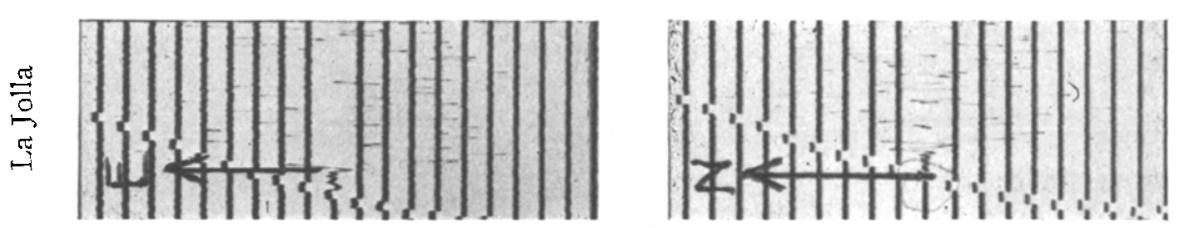

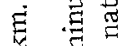

$+-\underline{y}$

o 11

$\stackrel{0}{=}$

11 5 क क

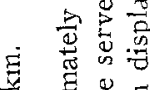

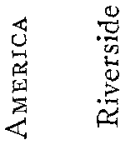

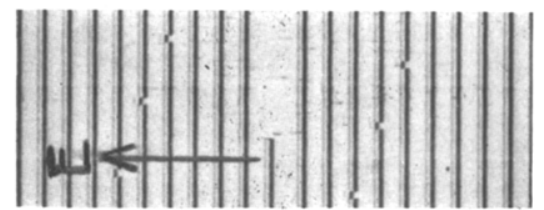

$+\quad$ 范

0 运

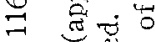

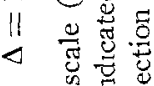

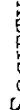
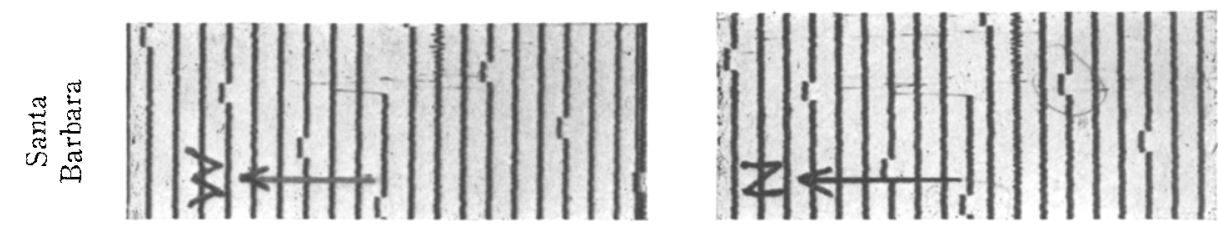

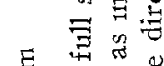

E

$\infty$.

$\stackrel{0}{=}$ 要

11 品

$<$ 焉焉

岁

空

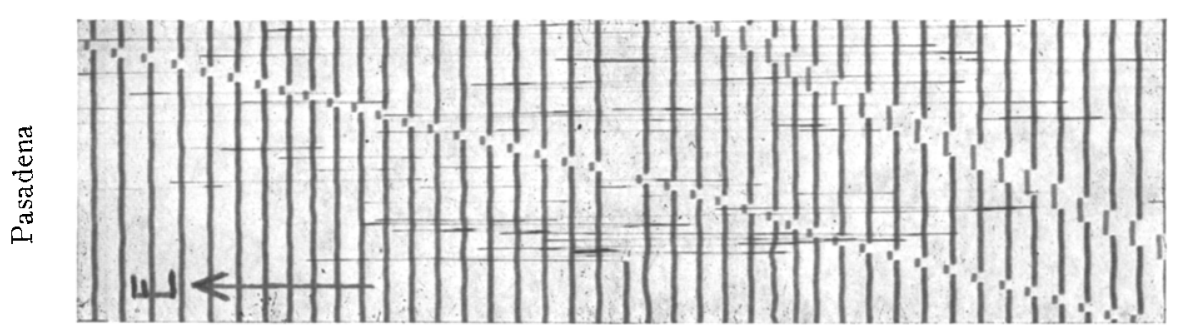

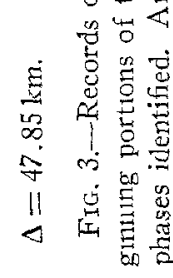


The beginning of motion on the records at Santa Barbara and Riverside is a sharp impulse of short period and considerable amplitude. This, therefore, is taken to be $\widetilde{P}$, especially since earlier phases possibly to be found at such epicentral distances should exhibit relatively small amplitude and longer period.

At La Jolla and Haiwee are seen impulses shortly after the beginning of motion which are identified as $\bar{P}$. The difference in the time of arrival of these impulses at these two stations is 13.3 seconds.

Hyperbolas constructed on the basis of these time differences, assuming the velocity of $\bar{P}$ to be 5.6 kilometers per second, intersect at or very near the point whose co-ordinates are $\phi=33^{\circ} 57^{\prime}$ north latitude, $\lambda=118^{\circ} 38^{\prime}$ west longitude, which, therefore, is taken as the epicenter.

The following table (Table III) exhibits findings on this basis.

TABLE III

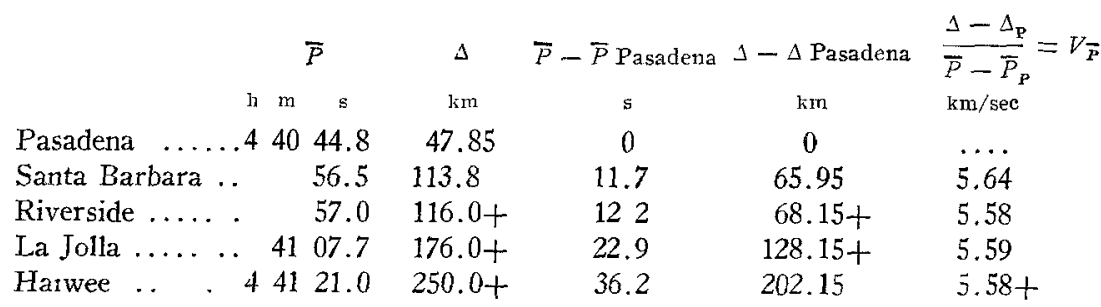

The values for $V_{\bar{P}}$ given in the table above as the quotient $\frac{\Delta-\Delta_{P}}{P-\bar{P}_{P}}$ are on the assumption of zero depth of origin. When allowance is made for a depth of origin of 15 kilometers, by applying the following corrections to the times of arrival at the several stations, namely, Pasadena, -0.4 second; Santa Barbara, -0.2 second; La Jolla, 0.0 second; and Haiwee, +0.1 second, better values for the velocity, $V_{\widetilde{P}}$, are found, as follows:

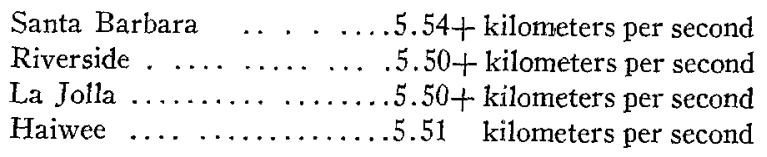

These findings suggest that the epicenter should be very slightly farther to the west. Any allowance for delay in arrival at Santa Barbara would add slightly to this. 
The Pasadena data were not used in fixing the location of the epicenter. Consequently, the excellent agreement among the values for $V_{\bar{P}}$ given above affords an independent check upon this, as well as on the identification of $\bar{P}$, and in some measure its velocity.

On the basis of the foregoing data the time at the origin was 4: $40: 36.0$ p.m., P.S.T. ( $0^{\mathrm{h}} 40^{\mathrm{m}} 36^{\mathrm{s}} 0$, G.C.T., August 31, 1930), with an error not exceeding 0.2 second.

The location of the epicenter is such that no precise instrumental determination of the depth of the origin is possible, but the data are consistent with a depth of 10 to 15 kilometers, while a depth noticeably greater than 15 kilometers is not consistent with the data.

\section{Aftershocks And Earlier Shocks}

In view of its strength this shock is remarkable because of the relatively small number of aftershocks which followed it. Only sixteen immediate aftershocks were recorded, mostly at Pasadena only, the last of these being at 6:28 a.m., P.S.T. (14 $28^{\mathrm{m}}$, G.C.T.), August 31. Only two or three further aftershocks were registered up to the end of September, 1930. Some, even, of the apparent aftershocks exh1bit peculiarities and seem not to have emanated from the same source. This contrasts strikingly with the case of the weaker Whittier shock where one hundred and fifty-five shocks were recorded during the first twenty-four hours after the main earthquake.

For three or more years previous to the shock here studied, its epicentral region was a persistent source of small shocks, several of which were reported felt in the districts adjacent to Santa Monica Bay. The earliest shock definitely assigned to this source took place on December 31, 1927, but at least one shock in 1926 may belong here. Previous to October, 1926, only one experimental sersmologic station was in operation here, so that the location of small shocks was indefinite.

\section{Geologic Notes}

At the surface the region affected by this shock is complex geologically, as the opening paragraphs suggest.

The nature of the rock at the epicenter, beneath the waters of Santa Monica Bay, is known only by inference.

Since the depth of the origin can be estimated only approximately, the nature of the rock at the origin is more uncertain than is sometimes the case. Near-by on land, both to the east and to the northwest, are very 
thick bodies of sediments, known definitely from oil-drilling operations to exceed ten thousand feet (about 3 kilometers) in vertical depth. Their true downward extension may be much in excess of this, estimated elsewhere in the region to be 8 kilometers ( 5 miles) or more. Notwithstanding this, it seems probable that the origin was deep enough to be located in the so-called "granitic" rock, forming the outer general crustal layer, beneath these thick sediments.

The seismologic stations at Pasadena. Mount Wilson, and Riverside are founded directly on granitic rock outcropping at the surface.

Granitic rock outcrops in the eastern part of the Santa Monica Mountains. Therefore, it is probable that the wave-paths from the origin to Pasadena and to Mount Wilson lay predominantly, if not wholly, in granitic rock.

This is also true of the path to Riverside, probably, even if the sedimentary rocks which form the San José Hills and the northern end of the Santa Ana Mountains should extend to depths substantially greater than 4 kilometers (2.5 miles). Our knowledge on this point is vague, but such a thickness seems hardly probable.

The station at Santa Barbara is built upon heavy boulder-laden alluvium, a stream deposit of moderate depth measured in scores to hundreds of feet, beneath which lies a sedimentary series of great but unknown depth. En route to this station the waves passed beneath the sedimentary body which occupies the Ventura basin, considered on stratigraphic grounds to be some 8 kilometers ( 5 miles) thick. The vertical thickness, of course, is unknown, but it must be of the same order, and it may be more. In this case the straight-line path from origin to station must traverse sedimentary material for a long distance, possibly a great part of its total length. The wave-path, however, probably traversed this underlyng granitic material for all but a very short distance, necessarily passing upward at the appropriate angle of refraction through the sediments beneath the station.

For nearly its entire distance the wave-path from the origin to the station at La Jolla followed a submarne path along which the rocks which form the ocean floor are known by inference only. However, there is some ground for thinking that sedimentary material is relatively thin. Moreover, while the rock at the surface at the station is slightly consolidated beach deposit, with Plocene strata near-by, the depth to granitic rock probably does not exceed a few hundred feet. However, the wavepath in any case probably traversed grantic rock throughout all but a negligible fraction of its length. 
From the origin to the stations at Hawwee and Tinemaha the waves first passed under the Santa Monica Mountains, at a depth comparable with that of the origin itself, then beneath the San Fernando Valley and the western end of the (granitic) San Gabriel Mountanns, then beneath the western part of the Mojave Desert (where crystalline metamorphic and Plutonic rocks, considered Pre-Cambrian in age, form the outcrops for the most part), continuing beneath the southeast flank of the (granitic) Sierra Nevada to the down-faulted depression of the Owens Valley in which the stations are located. Though loosely cemented tuff forms the surface rock at Haiwee, and basalt outcrops in a thin flow at Tinemaha. the waves must have passed through "granitic" material for all but a negligible part of these paths.

The surface geology is, like the surface form, much more complex, with corresponding effect on the energy manifestation of the shock, as already discussed.

The Santa Monica mountain block, extending to the east and to the west, north of the origin, is an anticlinal structure with a granitic core, which outcrops near the eastern end. With some doubt this granite is considered Jurassic in age. It is overlain by folded and extensively metamorphosed Cretaceous and Tertiary rocks, which include bodies of basalt. There are large bodies of slate and shale in the folded mass. Many faults traverse the mountain block in diverse directions, but in all probability these are no longer active.

To the northwest, beneath the Sim1 Hills, the Simi Valley, the Santa Susana Mountains and adjoining areas, are Upper Cretaceous and Tertiary sediments, largely sandstones, including considerable bodies of andesite and basalt, complexly folded in moderate degree, forming in general a synclinal structure. Numerous faults traverse this area, but there is no indication of any recent activity of any of these.

To the north is the small, deeply alluviated San Fernando Valley. north of which are the higher mountains of the Sierra Madre, stretching east and west. The eastern part of this range is known as the San Gabriel Mountains, with the San Bernardino Mountains still farther east, both formed of crystalline granitic and metamorphic rocks To the western part of the Sierra Madre various local names are given. The mountains here are made up of folded Tertiary sediments, which in certain places are known to extend to depths estimated on a stratigraphic basis to equal or exceed 8 kilometers ( 5 miles).

To the north of the San Gabriel Mountains is the Mojave Desert, a maturely eroded plain standing at an elevation of about 750 meters $(2,500$ 
feet), formed of crystalline metamorphic and Plutonic rocks with a few small basins of shallow Tertiary deposits and a thin cover of Quaternary and Recent detritus.

Directly to the north of the epicenter and north of the Sierra Madre 1s the granitic mass of the Tehachapi Mountans, which merge northward into the Sierra Nevada.

To the east and northeast of the epicenter are the Los Angeles plain and the San Gabriel Valley, with sediments extending to great but irregular depths in the western and southern parts, and directly to the east as well, beneath a variably thick cover of alluvium and wash gravel. Farther east are the San José Hills and the northern part of the Santa Ana Mountains, formed of folded Tertiary rocks. Beyond is the deeply alluviated Cucamonga Valley, the granitic Perris plain, and the alluviated San Jacinto Valley, where anomalously high intensity was reported.

To the east-southeast is the anticlinal mass of the Santa Ana Mountains with a Plutonic core overlain by Jurassic, Cretaceous, and Tertiary strata, w1th an area of Tertiary rock underlyng the flat coastal strip between the ocean and the foothills.

Lastly, to the southeast, south, southwest, and west from the epicenter are the waters of San Pedro Channel, the Pacific Ocean, and the Santa Barbara Channel. The submarine topographic contours, and the island areas which stand above sea-level, indicate that the area is a submerged portion of the Coast Range, but our knowledge is too scant to allow even generalized description or discussion of use in this study. Although the general structural conditions must be similar, for this reason it is not possible to associate this epicenter with any definitely known geologic fault.

\section{SUMMARY}

The occurrence of a moderately strong local earthquake in Santa Monica Bay, California, on August 30, 1930, is discussed and its epicenter and origin-time determined as follows : $\phi=33^{\circ} 57^{\prime}$ N., $\lambda=118^{\circ} 38^{\prime}$ $W, O=4.40 \cdot 360$ p.m., P S.T. $\left(0^{\mathrm{h}} 40^{\mathrm{m}} 36^{\mathrm{s}} 0\right.$, G.C.T., August 31, 1930).

The maximum intensity observed was VIII of the Modified Mercalli Intensity Scale of 1931, and the shock was perceptible at distances up to about 160 kilometers (100 miles) from the epicenter. The distribution of apparent intensity exhibits numerous irregularities which are discussed in the text. 
The depth of origin cannot be determined accurately, but the data are consistent with a depth of 10 to 15 kilometers ( 6 to 9 miles). A significantly greater depth is not consistent with the data.

The surface and subsurface geology of the region is discussed briefly.

Seismological Laboratory CarNegte Institution OF WAshington

California Institute of Technology

Pasadena, California

January 7, 1932 